\title{
Model Kepemimpinan Dan Manajemen Yesus Serta Implementasinya Terhadap Pertumbuhan Gereja Di Gereja-Gereja Cabang Gbi My Home Tanjung Pinang
}

\author{
Sri Murtini, ${ }^{1 *}$ Agiana Her Visnhu Ditakristi ${ }^{2}$, Susilo Susanto, ${ }^{3}$ Mitra Binariang Lase ${ }^{4}$ \\ Prodi PAK, STT Real Batam \\ Prodi Teologi, STT Real Batam \\ Prodi Teologi, STT Real Batam \\ srijoynaia@gmail.com
}

\begin{abstract}
The writing of this thesis departs from a problem that occurs in the GBI My Home Tanjungpinang branch churches, namely church growth in the GBI My Home Tanjungpinang branch church in quantity does not show significant growth. The author observes this because there is still weak leadership and management so that the church has not experienced significant growth in quantity. Therefore a leadership and management model of Jesus is needed to achieve maximum growth. In connection with that, in writing this thesis the writer formulated the problem as follows, First: What is the Jesus leadership model? Second: What is the Jesus management model? How to implement the Jesus leadership and management model for church growth in GBI My Home Tanjung Pinang branch churches? . To find answers, the authors conducted oral interviews and observations to the congregation and pastoral servants of GBI Teluk Sasah. After that the writer draws a conclusion by using a descriptive method that shepherds who have implemented Jesus' leadership and management model should have maximum church growth.
\end{abstract}

Keywords: Leadership, Management, Jesus; Church, Growth

\begin{abstract}
Abstrak
Penulisan tesis ini berangkat dari masalah yang terjadi di gereja-gereja cabang GBI My Home Tanjungpinang yaitu pertumbuhan gereja di gereja cabang GBI My Home Tanjungpinang secara kuantitas tidak menunjukkan pertumbuhan yang signifikan. Penulis mengamati hal tersebut dikarenakan masih lemahnya kepemimpinan dan manajemen yang ada sehingga gereja belum mengalami pertumbuhan yang signifikan secara kuantitas. Oleh sebab itu diperlukan model kepemimpinan dan manajemen Yesus guna mencapai pertumbuhan yang maksimal. Sehubungan dengan itu maka dalam penulisan tesis ini penulis merumuskan masalah sebagai berikut, Pertama: Bagaimanakah model kepemimpinan Yesus?, Kedua : Bagaimana model manajemen Yesus?, Bagaimana mengimplementasikan model kepemimpinan dan manajemen Yesus bagi pertumbuhan gereja di gereja-gereja cabang GBI My Home Tanjungpinang?. Untuk menemukan jawaban, penulis melakukan wawancara secara lisan dan observasi kepada jemaat dan pelayan pastoral GBI Teluk Sasah. Setelah itu penulis mengambil kesimpulan dengan menggunakan metode deskriptif bahwa gembala yang sudah mengimplementasikan model kepemimpinan dan manajemen Yesus seharusnya terjadi pertumbuhan gereja yang maksimal.
\end{abstract}

Keywords: Kepemimpinan, Manajemen, Yesus; Pertumbuhan, Gereja 


\section{PENDAHULUAN}

Kepemimpinan yang baik merupakan salah satu syarat bagi pertumbuhan, kestabilan, dan kemajuan dalam gereja. Gereja saat ini membutuhkan pemimpin-pemimpin yang kompeten untuk memberdayakan gereja Tuhan. Osei Mensah mengemukakan, "Umat Kristen di manapun di dunia sedang mengalami kebutuhan yang amat mendesak akan pemimpin-pemimpin yang terlatih.",

Seperti yang dipaparkan Fredy Simanjuntak, pemimpin gereja tidak bisa menutup mata pada masalah yang dihadapi para aktivis atau pelayan terlebih kepada jemaat yang dipimpinnya. Pemimpin rohani melalui gereja bertanggungjawab memberikan pelayanan, pertolongan dan pendampingan kepada jemaat secara holistik. Artinya bukan saja secara teologis alkitabiah rohaniah semata, tetapi juga secara kejiwaan (mental) dan badaniah. Sebagaimana Yesus memberikan contoh, mengetahui orang banyak sudah mengikuti Dia dan mendengarkan khotbah-Nya (makanan rohani), Ia sangat peduli dengan soal perut (makanan jasmani). ${ }^{2}$ Yesus memimpin murid-muridNya dengan hati bapa. Dalam perumpamaan anak yang hilang (Lukas 15: 11-32) Yesus mengajarkan hati seorang bapa yaitu penuh dengan kelembutan, keramahan dan pengampunan. Ketika anaknya telah pergi untuk meninggalkan bapanya dengan membawa harta warisan dan berfoya-foya dengan harta tersebut sehingga habislah harta itu dan ia kembali pulang kepada bapanya. Namun bapanya tidak mengusirnya malahan bapanya menyambutnya dengan penuh kehangatan dan pengampunan. Sekalipun dia telah melukai hati bapa, namun ia mengampuninya dan menerimanya kembali sebagai anak dalam keluarganya. Demikianlah hendaknya juga seorang gembala juga harus mampu untuk menjadi bapa rohani yang baik bagi anak-anak rohaninya.

Di tengah-tengah kehidupan Yesus bersama-sama dengan murid-muridNya, Yesus memberikan teladan kepada mereka. Teladan tersebut dapat dilihat dari tindakan-tindakan nyata yang Yesus lakukan dan tentunya memberi pengaruh yang besar kepada muridmuridNya. Berbicara tentang pengaruh, pengaruh seorang pemimpin tidak dapat dipaksakan kepada orang lain dan pengaruh terbesar muncul dari keteladanan yang ditunjukkan dalam kehidupan pemimpin itu sendiri. Yesus berkata dalam Yohanes 13: 15 "Sebab Aku telah memberikan suatu teladan kepada kamu, supaya kamu juga berbuat sama seperti yang telah Kuperbuat kepadamu." Artinya apa yang dilakukan oleh pemimpin, itu juga yang akan ditiru oleh pengikutnya. Pemimpin harus menghayati apa yang dipercayakan kepadanya dan menjadi teladan bagi pengikutnya. Karena setiap tindakannya mempunyai pengaruh yang kuat bagi orang lain. Dengan demikian orang lain akan terinspirasi dan termotivasi oleh teladan hidup yang ia tunjukkan daripada sekedar hanya

\footnotetext{
${ }^{1}$ Gottfried Osei- Mensah, Dicari Pemimpin Yang Menjadi Pelayan-Model Kepemimpinan Kristiani (Jakarta: Komunikasi Bina Kasih, 2006).

${ }^{2}$ Fredy Simanjuntak, "Kecerdasan Emosi Pemimpin Sebagai Tolok Ukur Gereja Yang Sehat," Real Didache 2, no. 1 (2017): 29-53.
} 
perkataan. Mengingat keteladanan itu amat penting, penulis mengamati bahwa masih ditemukan adanya pemimpin yang kurang maksimal dalam memberikan keteladanan hidup.

Ada banyak model-model manajemen yang sedang berkembang saat ini. Namun model-model tersebut memiliki kelemahan-kelemahan. Sebagai seorang gembala tentunya ia membutuhkan satu model manajemen yang baik yang perlu ia terapkan di gereja yang sedang ia gembalakan. Dalam Alkitab menunjukkan bahwa ada satu model manajamen yang berbeda dari manajemen yang ada di dunia. Model manajemen tersebut adalah model manajemen Yesus. Yesus adalah seorang yang ahli manajemen. Ketika ia menerima visi untuk memberitakan Injil, Yesus mempunyai manajemen yang unggul sehingga ketika ia tidak ada di bumi ini pun model manajemen yang ia pakai tidak pernah hilang dan sangat relevan untuk diimplementasikan pada saat ini terbukti dengan gereja masih ada hingga saat ini di seluruh dunia.

Untuk mencapai visi-Nya, hal utama yang dilakukan oleh Yesus adalah melakukan persiapan melalui doa. Sebelum Yesus merekrut murid-murid, Yesus terlebih dahulu berdoa. Yesus memulai pelayanan-Nya dengan doa. Bahkan di tengah-tengah kesibukan dan keramaian, Ia mengasingkan diri dan mengambil waktu untuk berdoa seorang diri (Mat. 14: 23, Mrk. 1: 35,) dan kadang Ia berdoa di pagi hari (Mrk. 1: 35, Luk. 4: 42), kadang pada malam hari (Mat. 14: 23), dan kadang Ia berdoa semalam-malaman (Luk. 6: 12). Kesibukan-kesibukan yang ada tidak menutup kesempatan-Nya untuk mengasingkan waktu bersekutu secara pribadi dengan Bapa-Nya melalui doa.

Setelah Yesus malakukan persiapan melalui doa, Ia merekrut orang-orang yang akan bersama-sama dengan Dia dalam pelayanan. Ia memilih orang-orang yang akan menyertai-Nya. Pada waktu Yesus berjalan di danau Galilea, Ia memanggil muridmuridNya yang pertama yaitu Simon yang disebut Petrus, Andreas saudaranya, Yakobus anak Zebedeus dan Yohanes anak Zebedeus, mereka adalah nelayan (Mat. 4: 18-22, Mrk. 1: 16-20, Luk. 5: 1-11). Kemudian Lewi, pemungut cukai (Mat. 9: 9-13), Filipus (Yoh. 1: 43-51). Kemudian murid-murid yang lain. Diantara banyak pengikutNya, Ia menetapkan ke dua belas murid itu menjadi rasul dan menjadi pemimpin gereja di kemudian hari. Mereka berasal dari latar belakang dan memiliki berbagai karakter. Walaupun ada satu orang yang akan mengkhianatinya, tetapi mereka adalah orang-orang pilihan untuk memimpin, melayani dan memberitakan Injil.

\section{METODE}

Adapun metode penelitian adalah sekumpulan peraturan, kegiatan dan prosedur yang digunakan oleh pelaku suatu displin ilmu ${ }^{3}$. Metode penelitian dapat dimengerti sebagai usaha untuk memenuhi dorongan yang kuat untuk mengetahui atau mendapatkan jawaban terhadap suatu permasalahan. Usaha tersebut langkah tertentu secara formal dan sistematis. Andreas B.Subagyo mengatakan bahwa metode penelitian adalah meliputi

\footnotetext{
${ }^{3}$ Rosady Ruslan, Metode Penelitian Public Relations Dan Komunikasi (Jakarta: Rajawali Pers, 2003).
} 
semua keterangan mengenai bagaimana penelitian dijalankan. ${ }^{4}$ Dalam penulisan karya ilmiah ini, penulis akan memaparkan penjelasan mengenai metode yang digunakan yaitu metode kualitatif.

\section{HASIL DAN PEMBAHASAN}

\section{Implementasi Model Kepemimpinan Yesus Bagi Pertumbuhan Gereja Menjadi Hamba}

Lukas 17: 10 menegaskan, "Demikianlah jugalah kamu. Apabila kamu telah melakukan segala sesuatu yang ditugaskan kepadamu, hendaklah kamu berkata: Kami adalah hamba-hamba yang tidak berguna; kami hanya melakukan apa yang harus kami lakukan." Artinya segala sesuatu yang dilakukan oleh seorang pemimpin sebagai seorang hamba dalam melayani umat yang Tuhan percayakan kepadanya, ia hanya melakukan apa yang seharusnya dilakukan. Oleh sebab itu tidak ada satupun yang dapat disombongkan oleh seorang pemimpin terhadap apapun yang telah ia perbuat untuk pelayanan karena ia hanya melakukan apa yang seharusnya ia lakukan.

\section{Menjadi Bapa}

Gambaran Bapa dapat dilihat dalam diri Yesus. Kata Yesus kepadanya: "Akulah jalan dan kebenaran dan hidup. Tidak ada seorangpun yang datang kepada Bapa, kalau tidak melalui Aku. Sekiranya kamu mengenal Aku, pasti kamu juga mengenal Bapa-Ku. Sekarang ini kamu mengenal Dia dan kamu melihat Dia" (Yohanes 14:6-7). Jadi, tujuan Yesus datang ke dunia adalah untuk memperkenalkan Bapa. Yesus telah membayar harga yang mahal agar kita mengenal Bapa, dengan cara disalibkan, dikutuk dan diejek. Kalau ada dosa, maka tidak akan ada damai, sehingga manusia perlu menerima Yesus sebagai Tuhan dan Juruselamat.

Dapat dikatakan, Yesus adalah pribadi seorang Bapa sebagaimana Yohanes 14:9 menyatakan "Kata Yesus kepadanya:”Telah sekian lama Aku bersama-sama kamu, Filipus, namun engkau tidak mengenal Aku? Barangsiapa telah melihat Aku, ia telah melihat Bapa; bagaimana engkau berkata: Tunjukkanlah Bapa itu kepada kami”. Maka, gambaran hati seorang Bapa dalam diri Yesus sebagai Allah Bapa dapat dilihat dalam: belas kasihan (Mat. 9: 36), kemurahan hati (Luk. 6: 36), merangkul (Luk. 15: 20), mengampuni, peduli (Mat. 9: 11-12), lemah lembut dan rendah hati (Mat. 11: 29), dan berkorban (Mrk. 10: 45).

\section{Menjadi Gembala}

Gembala yang ideal haruslah kuat, rela berkorban, dan tidak mementingkan diri sendiri. Seperti yang dinyatakan Tuhan Yesus sendiri yang adalah gembala Agung itu sendiri, "Akulah gembala yang baik. Gembala yang baik memberikan nyawanya bagi domba-dombanya; sedang seorang upahan yang bukan gembala, dan yang bukan pemilik

\footnotetext{
${ }^{4}$ Andreas B. Subagyo, Pengantar Riset Kuantitatif \& Kualitatif (Bandung: Yayasan Kalam Hidup, 2014).
} 
domba-domba itu sendiri, ketika melihat serigala datang, meninggalkan domba-domba itu lalu lari, sehingga serigala itu menerkam dan mencerai-beraikan domba-domba itu. Ia lari karena ia seorang upahan dan tidak memperhatikan domba-domba itu. Akulah gembala yang baik dan Aku mengenal domba-domba-Ku dan domaba-domba-Ku mengenal Aku, sama seperti Bapa mengenal Aku dan Aku mengenal Bapa, dan Aku memberikan nyawaKu bagi domba-domba-Ku" (Yoh 10:11-16).

\section{Menjadi Guru}

Murid-murid Yesus saat itu memanggil Yesus dengan sebutan guru. Ia mengajar dimana-mana tentang kerajaaan Allah dan kebenaran. Dalam Yoh 3:1-2 Yesus dipanggil sebagai guru oleh Nikodemus yang berstatus sebagai guru/pengajar orang Israel (Yoh 3:10). Artinya bahwa Yesus adalah Maha Guru. Disebutkan bahwa Yesus mengajar dengan kuasa dan hikmat Allah. Sewaktu Yesus datang ke dunia, ia memfokuskan untuk mengajar dan membimbing kedua belas muridNya agar mereka dapat meneruskan pelayanan yang dilakukan oleh Tuhan Yesus. Dalam setiap kesempatan dimanapun Yesus

melakukan pelayanan,Ia pasti melakukan pengajaran kepada banyak orang. Yesus menyebut dalam Yoh. 13:13-15 mengatakan bahwa "kamu menyebut Aku guru dan Tuhan, dan katamu itu tepat, sebab memang Akulah guru dan Tuhan. Jadi jikalau Aku membasuh kakimu, Aku yang adalah Guru dan Tuhan, maka kamu pun wajib saling membasuk kakimu; sebab Aku telah memberikan suatu teladan kepada kamu, supaya kamu juga berbuat sama seperti yang telah kuperbuat kepadamu".

\section{Implementasi Model Manajemen Yesus Bagi Pertumbuhan Gereja Merekrut}

Yesus merekrut murid-murid adalah untuk memenuhi kebutuhan orang-orang yang akan dilayaniNya. Yesus melihat ladang pelayanan begitu luas, dan memerlukan pekerja yang banyak. Hal inilah yang mendorong dan memotivasi Yesus merekrut muridmurid dan sekaligus untuk melanjutkan misi pelayan-Nya setelah ia naik ke surga. Kepribadian dan pelayanan murid-murid sangat berpengaruh terhadap kehidupan gereja masa kini. Yesus merekrut dua belas murid (Mat. 10: 1-4, Mrk. 3: 13-19, Luk. 6: 12-16). Yesus adalah perencana Agung, sebelum Ia memilih para murid-muriNya, yang kelak akan dipakai sebagai alatNya dan mempertanggung jawabkan kelanjutan pelayan-Nya, Yesus terlebih dahulu berdoa kepada Bapa (Luk. 6: 12). Tujuan utama Yesus merekrut muridmurid adalah supaya orang-orang tersebut dapat memberi kesaksian tentang hidup-Nya dan melanjutkan kembali pekerjaan-Nya sesudah Ia kembali kepada Bapa. Setelah Yesus merekrut murid-murid, mereka dibimbing dan dilatih dalam pelayanan. Yesus melatih murid-muridNya agar mereka mau mengikuti teladan hidupNya dalam setiap aspek kehidupan yang dijalaniNya. Ia membimbing dan melatih mereka untuk melayani. 


\section{Mengorganisir}

Yesus menetapkan dua belas orang untuk menyertai Dia dan diutusNya memberitakan Injil dan diberiNya kuasa untuk mengusir setan (Mark 13;14-15). Yesus mengorganisasi kedua belas orang tersebut dan menjadikan mereka menjadi kelompok inti. Dapat dilihat bahwa Yesus mengetahui pentingnya pengorganisasian kelompok inti dengan siapa Ia bisa membagi visi dan mempercayakan misiNya. Proses pengorganisasian tak sekedar mengumpulkan mereka, tetapi juga menanamkan hakikat pengajaranNya dan tuntutan untuk komitmen dan kesetiaan kepada Kerajaan Allah. Untuk mencapai tujuanNya, Yesus selalu menganjurkan murid-muridNya membentuk tim kerja atau kelompok kerja. Ia selalu melibatkan mereka dalam tugas-tugas yang ingin diselesaikanNya. Kendati Ia memulai dengan prakarsaNya sendiri, Ia tak bermaksud mengerjakanNya seorang diri. Dengan memilih dua belas murid sebagai langkah awal, Yesus ingin membuktikan bahwa jumlah tersebut dapat dikelola dalam pengorganisasian kelompok inti.

\section{Memperlengkapi}

Dalam Mrk. 3: 15, para murid diberikan kuasa untuk mengusir roh-roh jahat, melenyapkan segala penyakit dan segala kelemahan. Tanpa perlengkapan kuasa Ilahi ini, murid-murid akan mengalami kegagalan dalam menghadapi setiap tantangan dan hambatan yang ada dalam pelayanan. Kuasa Ilahi yang diberikan Tuhan dalam membantu para murid untuk lebih mengembangkan pelayanan mereka.

Sebelum Yesus naik ke surga, Ia memerintahkan para murid-Nya untuk menantikan janji Bapa di Yerusalem yaitu hari pencurahan Roh Kudus (Kis. 1: 4-5, 8). Kata Yesus kepada mereka: "Dan kamu akan menerima kuasa, kalau Roh Kudus turun ke atas kamu ....". Pada waktu hari pencurahan roh Kudus janji tersebut digenapi dan para murid menerima kuasa Roh Kudus untuk pergi memberitakan Injjl. Yesus mengerti bahwa orang yang melayani dan bekerja di ladang pelayanan-Nya sangat membutuhkan kuasa yang bersumber dari Allah.

\section{Mendelegasikan Tugas}

Yesus tidak memegang wewenang seorang diri. Ia memberi kesempatan kepada kedua belas orang itu untuk ambil bagian. Ia medelegasikan tugas kepada mereka untuk pergi dalam tim kecil yang terdiri dari dua orang (Mrk. 6:7, Lukas 10:1). Yesus mendelegasikan wewenang: "Ia memberi mereka kuasa ...." (Markus 6:6b). Sebelum itu Yesus mempersiapkan mereka untuk mengantisipasi kesulitan dan hambatan (Markus 6: 6b-13).

Ketika Yesus masih hidup tugas utamaNya adalah mengajar dan memberitakan injil. Namun sebelum Ia naik ke surga, Ia mendelegasikan tugas tersebut kepada muridmuridNya. "Karena itu pergilah, jadikanlah semua bangsa murid-Ku dan baptislah mereka 
dalam nama Bapa dan Anak dan Roh Kudus, dan ajarlah mereka melakukan segala sesuatu yang telah kuperintahkan kepadamu. Dan ketahuilah, Aku menyertai kamu senantiasa sampai kepada akhir zaman" (Mat. 28: 19-20). Dapat dikatakan bahwa tugas tersebut adalah tugas yang berat, namun Yesus juga mengetahui bahwa mereka akan melakukan pekerjaan yang lebih besar dari apa yang Yesus pernah kerjakan (Yoh. 14: 12).

\section{Mengutus}

Maka Yesus memanggil kedua belas muridNya, lalu memberikan tenaga dan kuasa kepada mereka untuk menguasai setan dan untuk menyembuhkan penyakit-penyakit. Dan Ia mengutus mereka untuk memberitakan kerajaan Allah dan untuk menyembuhkan orang (Luk. 9: 1-2).

Para murid bukan saja diutus untuk memberitakan Injil (Mrk. 3: 14) tetapi juga menyatakan pemerintahan, kuasa, dan wibawa kerajaan Allah dengan jalan berperang melawan iblis, mengusir roh-roh jahat dan menyembuhkan segala macam penyakit (Mat. 10: 11, 7-8).

\section{Melakukan Supervisi}

Dalam pelayanan Yesus melakukan supervisi terhadap para murid yang telah kembali dan melaporkan pelayanan mereka (Luk. 10: 17-20). Dalam laporan mereka, para murid bersukacita karena apa yang terjadi dalam pelayanan mereka. Hal tersebut dapat membuat para murid menjadi sombong sehingga Yesus mengingatkan bahwa sukacita meraka seharusnya didasarkan pada fakta bahwa Allah memilih mereka untuk menjadi milikNya. Dalam hal tersebut Yesus mensupervisi para murid agar mereka tidak menyimpang dan mereka dapat melakukan pekerjaan pelayanan dengan baik. Yesus melakukan koreksi dan evaluasi agar para murid melakukan pelayanan dengan baik. Oleh sebab itu, dalam pelayanan supervisi merupakan komponen penting untuk tercapainya apa yang diharapkan.

\section{Meregenerasi}

Setiap pemimpin perlu menyadari bahwa dirinya hanya bisa melayani sebagai pemimpin dalam jangka waktu yang terbatas, sehingga ia harus menyiapkan pengganti sebelum masa kepemimpinannya berakhir. Musa mempersiapkan Yosua untuk menjadi pengganti dirinya. Rasul Paulus mempersiapkan Timotius, Titus, dan beberapa orang lagi untuk meneruskan pelayanannya. Tuhan Yesus mempersiapkan dua belas murid untuk meneruskan pelayanan-Nya di bumi ini.Pola yang dipakai oleh Yesus untuk regenerasi adalah: 1) Memanggil kedua belas murid (Mat. 10: 1-4),. 2) Mempersiapkan murid-muridNya menghadapi penganiayaan (Mat. 10: 16-33), 3) Mengutus murid-murid-Nya (Mat. 10: $5-15)$. 
Yesus memakai sebagian waktu selama tiga setengah tahun pelayanan-Nya untuk membina murid-muridNya agar mereka bisa meneruskan pelayanan-Nya setelah Ia pergi (Markus 3: 14-15). Ia menetapkan dua belas murid untuk menyertai-Nya dan untuk diutusNya untuk memberitakan Injil. Mereka diberikan kuasa untuk mengusir setan. Oleh sebab itu berkali-kali Yesus memberitahukan bahwa Ia akan ditangkap, disiksa, mati, bangkit kembali dan naik ke sorga. Dengan itu Yesus menyiapkan para murid untuk jadi penerus pekerjaan Yesus. Ketika tiba saat serah terima maka Yesus menyerahkan tugas-tugas dan menjanjikan penyertaan dan dukungan-Nya (Matius 28: 18-20).

\section{KESIMPULAN}

Model kepemimpinan Yesus bagi pertumbuhan gereja adalah model kepemimpinan seorang hamba, model kepemimpinan seorang bapa, model kepemimpinan seorang gembala, dan model kepemimpinan seorang guru. Model manajemen Yesus bagi pertumbuhan gereja adalah merekrut, mengorganisir, memperlengkapi, medelegasikan tugas, mengutus, supervisi, dan regenerasi. Gembala harus mengimplementasikan model kepemimpinan dan manajemen Yesus secara bersama-sama untuk mencapai pertumbuhan gereja dalam kepemimpinan meliputi: dalam melayani gembala harus menjadi hamba, gembala harus menjadi bapa, gembala harus menjadi gembala, dan gembala harus menjadi guru bagi pengerja dan jemaat yang digembalakan. Dalam manajemen meliputi: gembala sebagai pemimpin harus merekrut pengerja/pelayan jemaat, gembala harus mogorganisir pengerja dan pelayanan yang ada, gembala harus memperlengkapi pengerja dan jemaat, gembala harus mendelegasikan tugas kepada pengerja, gembala harus mengutus pengerja, gembala harus melakukan supervisi kepada pengerja, gembala harus meregenerasi pemimpin baru.

Gembala sebagai pemimpin harus mau menerima masukan dari pengerja dan

tidak membuat mereka menjadi saingan tetapi menganggap mereka sebagai mitra kerja untuk mencapai pertumbuhan gereja.

\section{KEPUSTAKAAN}

Mensah, Gottfried Osei-. Dicari Pemimpin Yang Menjadi Pelayan-Model Kepemimpinan Kristiani. Jakarta: Komunikasi Bina Kasih, 2006.

Ruslan, Rosady. Metode Penelitian Public Relations Dan Komunikasi. Jakarta: Rajawali Pers, 2003.

Simanjuntak, Fredy. "Kecerdasan Emosi Pemimpin Sebagai Tolok Ukur Gereja Yang Sehat." Real Didache 2, no. 1 (2017): 29-53.

Subagyo, Andreas B. Pengantar Riset Kuantitatif \& Kualitatif. Bandung: Yayasan Kalam Hidup, 2014. 